\title{
Bo-Gan-Whan regulates proliferation and migration of vascular smooth muscle cells
}

\author{
Kang Pa Lee ${ }^{1} \mathbb{D}$, Jai-Eun Kim²${ }^{2}$, Hyuck Kim³ ${ }^{3}$, Hae Ryong Chang ${ }^{1}$, Dae Won Lee ${ }^{1}$ and Won-Hwan Park ${ }^{3^{*}}$
}

\begin{abstract}
Background: Bo-Gan-Whan (BGH), a Korean polyherbal medicine, is used as a hepatoprotective drug. It has six natural sources, and has been demonstrated to have anti-oxidative, anti-cancer, and anti-inflammatory properties; however, its effect on vascular diseases remains unclear.

Methods: Cell viability and proliferation assays were employed using an EZ-Cytox Cell Viability Assay Kit. Plateletderived growth factor (PDGF)-BB-induced vascular smooth muscle cell (VSMC) migration was measured by scratch wound healing assay and Boyden chamber assay. The expression levels of the phosphorylated signaling proteins relevant to proliferation, including extracellular signal-regulated kinase (ERK) 1/2 and p38 mitogen-activated protein kinase (MAPK) were determined by western blot analysis. Chromatogram and mass analysis were employed by Ultra Performance Liquid Chromatography (UPLC) system. Cell prolife ration and migration were also explored using the PDGF-BB-induced aortic sprout assay.

Results: BGH (100-500 $\mu \mathrm{g} / \mathrm{mL})$ significantly inhibited the proliferation and migration of PDGF-BB-stimulated VSMCs through the reduced phosphorylation of ERK1/2 and p38 MAPK in comparison to untreated PDGF-BB-stimulated VSMC. Moreover, we identified the paeoniflorin as the major composition of BGH.
\end{abstract}

Conclusions: We suggest that BGH may have an anti-atherosclerosis effect by inhibiting the proliferation and migration of PDGF-BB-stimulated VSMCs through down-regulation of ERK1/2 and p38 MAPK phosphorylation.

Keywords: Bo-Gan-Whan, Vascular smooth muscle cells, Platelet-derived growth factor-BB, Extracellular signalregulated kinase 1/2, p38 mitogen-activated protein kinase

Abbreviations: BGH, Bo-Gan-Whan; BSA, Bovine serum albumin; DMEM, Dulbecco's Modified Eagle's Medium; ERK, Extracellular signal-regulated kinase; FBS, Fetal bovine serum; MAPK, Mitogen-activated protein kinases; PDGF, Platelet-derived growth factor; UPLC, Ultra Performance Liquid Chromatography; VSMC, Vascular smooth muscle cell

\section{Background}

Vascular disorders are among the major causes of health problems or death, particularly in western countries [1]. Acute coronary diseases are associated with mortality and therefore require urgent medical attention such as stent therapy to restore blood flow to a narrowed blood vessel [2]. However, the stent therapy has an inevitable risk factor such as vascular restenosis [3]. Particularly in vascular lesion, abnormal physiological responses of smooth muscle cells (VSMCs) underlying cell migration

\footnotetext{
* Correspondence: diapwh@dongguk.ac.kr

${ }^{3}$ Department of Diagnosis, College of Korean Medicine, Dongguk University, Dongguk-Ro 32, Goyang, Gyeonggi-do 10326, Republic of Korea

Full list of author information is available at the end of the article
}

and proliferation are the major mechanism of developing vascular restenosis [4]. Therefore, controlling pathological progressions of VSMCs is one of the major methods under consideration to prevent the restenosis $[5,6]$.

Several studies have shown that VSMCs motility and hyperplasia in response to arterial pathogenesis were stimulated by platelet-derived growth factor (PDGF) [7, 8]. PDGF-BB can stimulate arterial pathogenesis signal cascades such as PDGF beta receptor and its downstream signaling molecules, consequently resulted in an increasing phosphorylated p38 mitogen-activated protein kinase and activated of extracellular signal-regulated kinase $1 / 2[9,10]$.

Recently, functional foods or medical food supplements have been used in health-promotion or disease 
prevention-strategies. This requires the discovery and development of products from natural sources that may provide alternative interventions to currently approved medicine $[11,12]$. The majority of patients who undergo angioplasty through stents, require inevitable medication for a long period of time to avoid the progression or reoccurrence of restenosis [13]. For these reasons, Korean traditional medicines have been used as an alternative to treat diverse human diseases and to maintain good health [14]. Thus, in this study, we investigated the efficacy of Bo-Gan-Whan (BGH) in restenosis. According to the Korean medical encyclopedia, BGH has been traditionally prescribed for infirmed liver and for general hepaticprotection. However, to date, the anti-migration and proliferation of VSMCs after treatment with BGH is not fully understood. Hence, we attempted to investigate the antirestenosis effect of BGH on PDGF-BB-stimulated VSMCs to provide fundamental data for alternative medicine development.

\section{Methods}

\section{Preparing reagents}

The EZ-Cytox Cell Viability Assay Kit were purchased from Daeil Lab Service (Seoul, Korea) and cell culture materials were purchased from Gibco-BRL (Gaithersburg, MD, USA), respectively. Recombinant PDGF-BB was obtained from R\&D systems (Minneapolis, MN, USA). Specific antibodies for GAPDH, ERK1/2, phosphorylation of ERK1/2, p38, and phosphorylation of p38 for analysis of western blots, were purchased from Santa Cruz Biotechnology (Santa Cruz, CA, USA). All other chemicals were purchased from Sigma (St. Louis, MO, USA).

\section{Plant material and extraction}

BGH (5 g Ostericum koreanum rhizome, 5 g Anglicae gigas root, $5 \mathrm{~g}$ Ledebouriella seseloides root, 5 g Paeonia lactiflora root, $5 \mathrm{~g}$ Rehmannia glutinosa root, and $5 \mathrm{~g}$ Cnidium officinale. Makino) was obtained from Dongguk University Oriental Hospital, Korea which has been prepared specifically for this study from the commerciallyavailable products. The plants were blended (a total of $30 \mathrm{~g}$ ), and the crude powder was boiled in $1000 \mathrm{~mL}$ of sterile deionized water at $100{ }^{\circ} \mathrm{C}$ for $3 \mathrm{~h}$. The aqueous extracts were concentrated and evaporated at $60{ }^{\circ} \mathrm{C}$ under vacuum. The extract was then lyophilized by freeze-drying at $-60{ }^{\circ} \mathrm{C}$.

\section{Isolation and cultivation of primary VSMCs from rats}

Aortic VSMCs were isolated from male Sprague-Dawley (SD) rats following previously described protocols [15]. VSMCs were cultured in Dulbecco's Modified Eagle's Medium (DMEM) low glucose supplemented with $10 \%$ fetal bovine serum (FBS), $100 \mathrm{U} / \mathrm{mL}$ penicillin, $100 \mathrm{~g} / \mathrm{mL}$ streptomycin, and $200 \mathrm{mM}$ glutamine at $37{ }^{\circ} \mathrm{C}$ under a humidified $95 \%$ air $/ 5 \% \mathrm{CO}_{2}$ mixture (v/v). All protocols for animal experiments were approved by the ethics committee of Dongguk University (IACUC-2014-009).

\section{The cell viability assay}

VSMCs were seeded at $2 \times 10^{4}$ cells $/ \mathrm{mL}$ in a 96-well microplate containing DMEM and incubated for $24 \mathrm{~h}$. The cells were then incubated with different concentrations of BGH $(10-500 \mu \mathrm{g} / \mathrm{mL})$ in DMEM for $24 \mathrm{~h}$. The cell viability of VSMCs was determined by the EZ-Cytox Cell Viability Assay Kit at $450 \mathrm{~nm}$. The effects of BGH were then determined based on the relative cell viability of the treated group in comparison to the untreated group.

\section{The assay of VSMCs' proliferation}

VSMCs $\left(2 \times 10^{4}\right.$ cells $\left./ \mathrm{mL}\right)$ were seeded in a 96-well microplate containing DMEM and incubated for $24 \mathrm{~h}$. These cells were incubated in serum-free media for $12 \mathrm{~h}$. VSMCs were then incubated with different concentrations of BGH $(10-500 \mu \mathrm{g} / \mathrm{mL})$ and PDFG-BB (10 ng/ $\mathrm{mL}$ ) for an additional $24 \mathrm{~h}$. The proliferation rate of VSMCs was determined by the EZ-Cytox Cell Viability Assay Kit at $450 \mathrm{~nm}$.

\section{Scratch wound healing assay}

VSMCs $\left(4 \times 10^{4}\right.$ cells $\left./ \mathrm{mL}\right)$ were incubated in a 6-well dish in growth medium for $24 \mathrm{~h}$ and then incubated in serum-deprivation media for $24 \mathrm{~h}$. To induce a migrating zone in transverse scratch wound, each monolayer of VSMCs was scratched with a sterilized $200 \mu \mathrm{L}$-tip. Subsequently, VSMCs were treated with PDGF-BB (10 ng/ $\mathrm{mL})$ and BGH (100-500 $\mu \mathrm{g} / \mathrm{mL})$ for an additional $24 \mathrm{~h}$. VSMC morphological changes were examined and recorded using an inverted microscope and CCD camera (IX71; Olympus, Tokyo, Japan). The migrating zone was examined and analyzed between $0 \mathrm{~h}$ to 24 using Image J software.

\section{Boyden chamber assay}

The PDGF-BB-mediated VSMC migration assay was performed using a Boyden chamber, as previously described [15]. VSMCs were harvested from the grown-up in serum-free media for $24 \mathrm{~h}$. A density of $1 \times 10^{6} \mathrm{cell} / \mathrm{mL}$ of VSMCs in $50 \mu \mathrm{L}$ DMEM supplemented $0.1 \%$ bovine serum albumin (BSA) in the upper chamber, which was then inserted in the lower chamber containing PDGF-BB $(10 \mathrm{ng} / \mathrm{mL})$ and various concentrations of BGH (100$500 \mu \mathrm{g} / \mathrm{mL}$ ) in $28 \mu \mathrm{L}$ DMEM supplemented $0.1 \%$ BSA. The migrated VSMCs on the membrane for $90 \mathrm{~min}$ were analyzed using Image J software.

\section{Western blot analysis}

VSMC lysates were separated by electrophoresis using $12 \%$ acrylamide gels and then transferred to polyvinylidene 
difluoride membranes in transfer buffer at $4{ }^{\circ} \mathrm{C}$ for $2 \mathrm{~h}$. The membrane was treated with Tris-buffered saline containing $5 \% \mathrm{BSA}$ at room temperature for $1 \mathrm{~h}$ and then incubated overnight at $4{ }^{\circ} \mathrm{C}$ with antibodies for phosphorylated ERK1/2 (p-ERK1/2) or p38 (p-p38), total ERK1/2 (T-ERK1/2) or p38 (Tp38), and GAPDH at 1:1000 dilution. The membranes were washed in Tris-buffered saline containing $0.1 \%$ Tween 20, and then incubated with a 1:1000 dilution of anti-IgG secondary antibody conjugated to horseradish peroxidase for $1 \mathrm{~h}$. The expression levels of each protein were analyzed via chemiluminescence and quantified using Image J Software.

\section{The assay of aortic sprout ring growth}

Ex vivo properties of vessels were measured by an aortic sprout assay, as previously described [16]. Owing to the protocol, the endothelium and adventitium of the aorta from SD rats (5-weeks-old, $n=4$ ) were removed mechanically and enzymatically, and the internal vessels were cut into $1-\mathrm{mm}^{2}$ strips. The strips were embedded in 48well plates coated with matrigel, and then treated with PDGF-BB (10 ng/mL) and BGH (100-500 $\mu \mathrm{g} / \mathrm{mL})$ in FBS-free DMEM for five days. The strips were stained with Diff-Quik (Baxter Healthcare) and photographed, and the length of sprout was analyzed using Image J software.

\section{Ultra -performance liquid chromatography (UPLC)-based analysis}

UPLC-based fingerprinting was performed with an UPLC system (Waters, Corporation, Milford, USA), equipped with a quaternary pump, a vacuum degasser, diode-array detector and Waters software. Separation was performed using a UPLC ${ }^{\mathrm{rm}}$ BEH $\mathrm{C}_{18}$ column $(1.7 \mu \mathrm{m}, 2.1 \mathrm{~mm} \times$ $50 \mathrm{~mm})$. The mobile phase was a mixture of $0.1 \%(\mathrm{v} / \mathrm{v})$ of acetonitrile and water containing $0.1 \%(\mathrm{v} / \mathrm{v})$ formic acid at a flow rate of $0.3 \mathrm{~mL} / \mathrm{min}$. A standard solution containing paeoniflorin (Sigma-Aldrich, MO, USA) was prepared by dissolving these compounds in distilled water $(10 \mathrm{mg} /$ $100 \mathrm{~mL})$. The solution was filtered through a $0.45 \mu \mathrm{m}$ membrane filter, after which UPLC was performed.

\section{Statistical analysis}

GraphPad Prism (GraphPad, San Diego, USA) was used to analyze statistical data analysis. The results were presented as the mean \pm standard error (SE) of at least three independent experiments $(n \geq 3)$. The results were assessed using a Student's t-test and one-way ANOVA followed by Tukey's multiple range test. Statistical significance was considered at $P<0.05$.

\section{Results}

BGH inhibits the proliferation of PDGF-BB-induced VSMCs To test the effect of BGH on PDGF-BB-induced proliferation of VSMCs, a 2,3-bis [2-methyloxy-4-nitro-5sulfophenyl]-2H-tetrazolium-5-carboxanilide (XTT) assay was employed using EZ-Cytox Cell Viability Assay Kit. The data demonstrated that $\mathrm{BGH}$ did not induce altered cell viability and morphology at defined concentrations up to $500 \mu \mathrm{g} / \mathrm{mL}$ compared with the untreated group $(n=3$, Fig. 1a). Treatment with BGH at varying concentrations between 100-500 $\mu \mathrm{g} / \mathrm{mL}$ inhibited PDGF-BB (10 ng/mL)induced proliferation of VSMCs in a dose-dependent manner. The optimum effect was observed at $500 \mu \mathrm{g} / \mathrm{mL}$ of BGH ( $n=3$, Fig. $1 \mathrm{~b})$.

BGH inhibits the migration of PDGF-BB-stimulated VSMCs One of the causes of atherosclerosis is an abnormal migration of VSMCs in pathogenic condition that be induced by PDGF and cytokines [7, 8]. Therefore, we determined the measuring anti-migration effect of $\mathrm{BGH}$ by the scratch wound healing and the boyden chamber assay with PDGF-BB stimulation. First, in the case of scratch wound healing assay, BGH significantly inhibited the PDGF-BBstimulated migration of VSMCs as shown by the reduction of the scratch area, in a dose-dependent manner
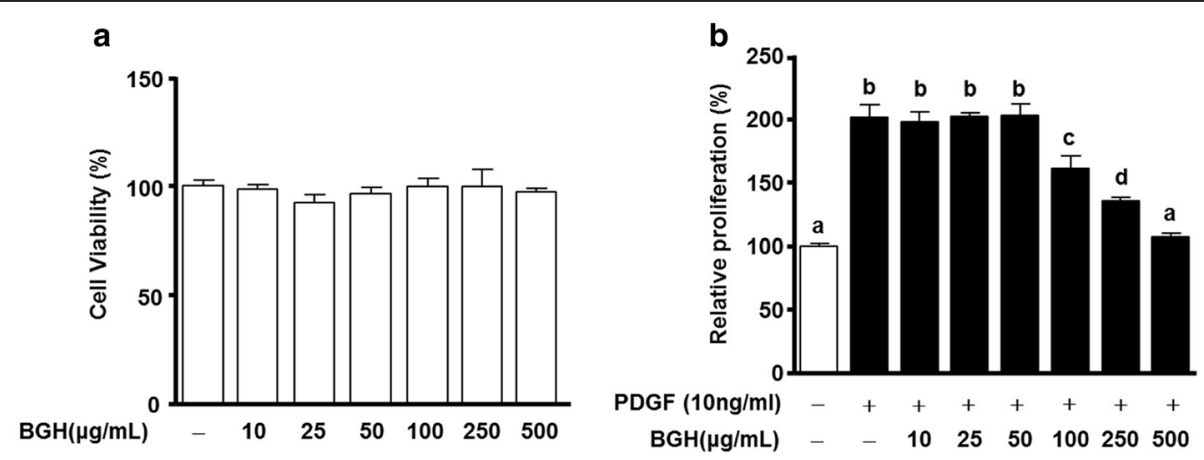

Fig. 1 The effect of Bo-Gan-Whan (BGH) on proliferation of PDGF-BB-stimulated VSMCs. a Cell Viability and $\mathbf{b}$ Proliferation Rates of VMSCs after $24 \mathrm{~h}$ treatment with BGH in a dose-dependent manner $(10,25,50,100,250$, and $500 \mu \mathrm{g} / \mathrm{mL})$. The graph shows the representative cell viability from three independent experiments. Data are presented as mean \pm standard error. Values with the same superscript letter are not significantly different as analyzed by Tukey's multiple range test $(P<0.05)$ 
(Fig. 2). The data confirms that the maximum inhibitory effect of BGH treatment on PDGF-BB (10 ng/mL)-induced cell migration was achieved at $500 \mu \mathrm{g} / \mathrm{mL}(n=3$, Fig. 2). Next, the boyden chamber assay was performed to assess whether BGH could inhibit cell migration of the PDGF-BB-stimulated VSMCs within a short period. VSMCs were treated with BGH $(100,250$, and $500 \mu \mathrm{g} /$ $\mathrm{mL})$ and PDGF-BB (10 ng/ mL) for $90 \mathrm{~min}$. As shown in Fig. 3, PDGF-BB (10 ng/ml) increased VSMC migration, whereas BGH (100, 250, and $500 \mu \mathrm{g} / \mathrm{mL}$ ) significantly inhibited PDGF-BB (10 ng/ml)-induced migration in a dose-dependent manner ( $n=6$, Fig. 3 ).

\section{$B G H$ reduces the phosphorylation of p38 MAPK and ERK1/2 in PDGF-stimulated VSMCs}

Several studies have suggested that a key signal cascade in PDGF-BB-induced VSMCSs is p38 MAPK and ERK1/ $2[10,15]$. Therefore, we tested whether BGH inhibits the expression of phosphorylated p38 MAPK and ERK1/ 2 in PDGF-BB-induced VSMCs using western blot analysis. PDGF-BB (10 ng/mL) increased the phosphorylation of ERK1/2 and p38 MAPK in VSMCs $(n=4$, Fig. 4$)$. The phosphorylation of p38 MAPK was only reduced at a concentration of $500 \mu \mathrm{g} / \mathrm{mL} \mathrm{BGH}$ (Fig. 4b) whereas the phosphorylation of ERK1/2 was inhibited by BGH treatment $(100,250$, and $500 \mu \mathrm{g} / \mathrm{mL})$ in a dose-dependent manner (Fig. 4c).

\section{BGH inhibits PDGF-BB-stimulated sprout outgrowth}

To confirm the migration and proliferation of VSMCs ex vivo, the aortic sprout outgrowth assay was performed. PDGF-BB significantly increased the sprout outgrowth from the aortic strips, whereas varying concentrations of $\mathrm{BGH}(100,250$, and $500 \mu \mathrm{g} / \mathrm{mL})$ induced elimination of the PDGF-BB-induced outgrowths in a dose-dependent manner. This inhibitory response reached a maximum level at $500 \mu \mathrm{g} / \mathrm{mL}$ of BGH ( $n=3$; Fig. 5$)$.

\section{The analysis of chromatogram and mass in the composition of $\mathrm{BGH}$}

As shown in Fig. 6, to identify the composition of BGH, we performed UPLC-based analysis. First, we detected a major peak between Paeonia lactiflora root and $\mathrm{BGH}$ at approximately 9.00 min employed UV-spectrum (Fig. 6a). Next, we identified paeoniflorin from the mass of constituents in its retention time, which was of 498.2003 molecular weights (Fig. 6b). Finally, we found BGH and paeoniflorin according to MS spectra among Paeonia lactiflora root (Fig. 6c).

\section{Discussion}

In this study, we demonstrated that Bo-Gan-Whan (BGH), a Korean polyherbal medicine, has an inhibitory effect on VSMC migration and proliferation in response to PDGF-BB as revealed by the results obtained from the scratch-wound healing and Boyden chamber assay and sprout aortic ring assays, respectively. Moreover, it was demonstrated through western blot analysis that the modulation of MAPKs is the major signal that is activated in the pathogenesis of VSMCs through activation of the ERK1/2 and p38 MAPK pathways. These results were confirmed from the ex vivo analysis of PDGF-BB-induced VSMCs' migration and proliferation. The data on ex vivo analysis, through outgrowth of vessel sprouts from the a

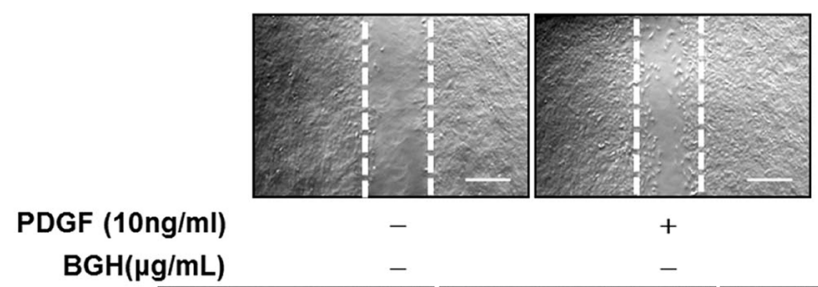

\section{b}

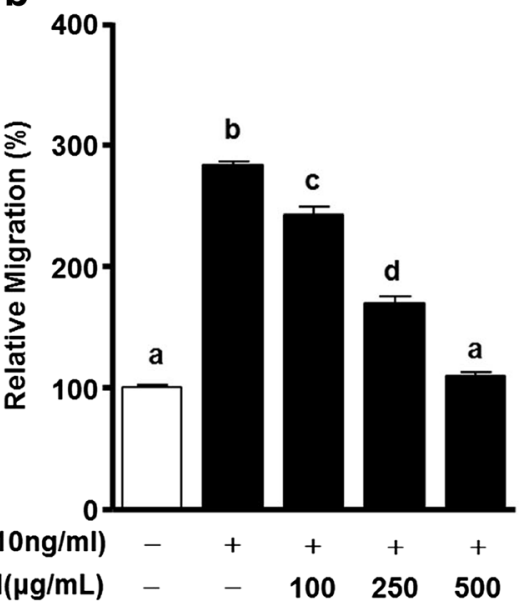

Fig. 2 Effects of Bo-Gan-Whan (BGH) on scratch wound-healing of PDGF-BB-stimulated VSMCs. VSMCs were treated with BGH (100-500 $\mu$ g/mL) and PDGF-BB (10 ng/mL) for $24 \mathrm{~h}$. a Dotted white lines indicate the initial scratches. Magnification, 100x. Bar $=500 \mu \mathrm{m}$. $\mathbf{b}$ Migration rates of VMSCs relative to the untreated group (\%). Results are presented as mean \pm standard error. Values with the same superscript letter are not significantly different as analyzed by Tukey's multiple range test $(P<0.05)$ 

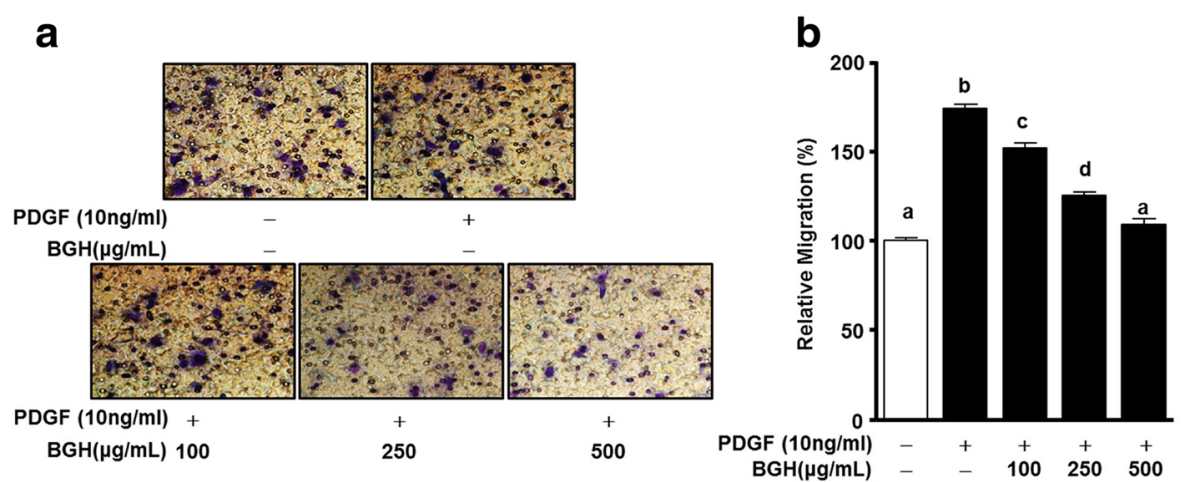

Fig. 3 Effects of Bo-Gan-Whan (BGH) on migration of PDGF-BB-stimulated VSMCs. VSMCs were treated with BGH $(100,250$, and 500 $\mu \mathrm{g} / \mathrm{mL})$ and PDGF-BB $(10 \mathrm{ng} / \mathrm{mL})$ for $90 \mathrm{~min}$. a Microphotographs of the migration patterns of VSMCs on membranes. The spots are Diff quick-stained cells. Magnification $=200 \times$. $\mathbf{b}$ Migration rates of BGH and PDGF-BB-treated VMSCs relative to the untreated group (\%). Results are presented as mean \pm standard error. Values with the same superscript letter are not significantly different as analyzed by Tukey's multiple range test $(P<0.05)$

aortic strips assay, show that BGH treatment can significantly reduce VSMC migration and proliferation after PDGF-BB stimulation.

Abnormal proliferation of VSMCs is a key to the vascular pathological conditions such as atherosclerosis and restenosis. Moreover, excessive migration of VSMCs in vascular walls is one of the critical causes of vascular neointima formation [4]. Therefore, suppression of VSMC migration and proliferation may be one of the protective strategies against restenosis or neointima formation in atherosclerosis. Specifically, the present study shows that BGH could be a potential medicine or supplement for PDGF-BB-stimulated vascular remodeling since it can remarkably inhibit VSMC proliferation and migration at the highest dosage $(500 \mu \mathrm{g} / \mathrm{mL}$ of $\mathrm{BGH})$. Therefore, BGH could be a potential therapeutic agent for preventing or

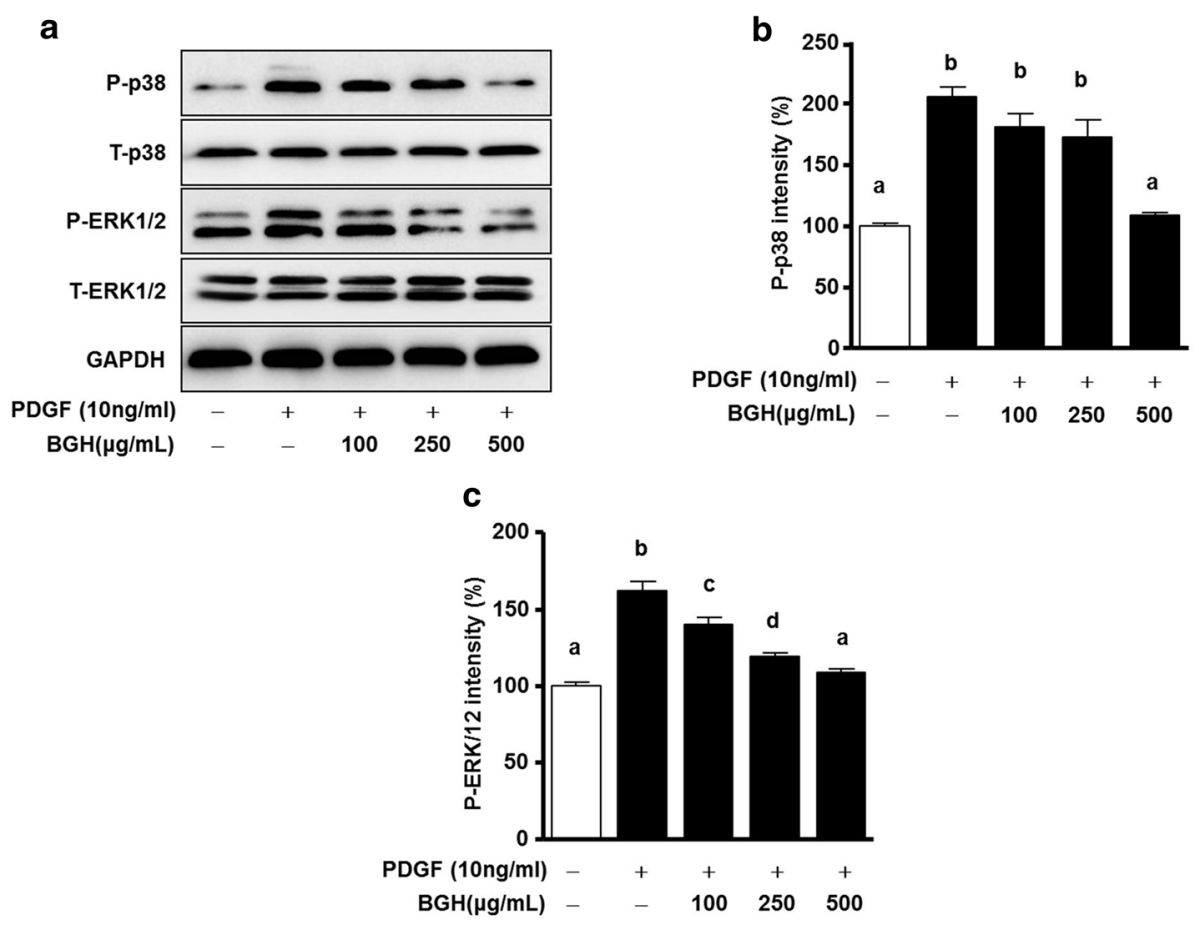

Fig. 4 Effect of Bo-Gan-Whan (BGH) on PDGF-BB induced phosphorylation of ERK1/2 and P38 MAPK in VSMCs. VSMCs were pretreated with or without $(100,250$, and $500 \mathrm{mg} / \mathrm{mL}$ ) BGH for $1 \mathrm{~h}$ and then stimulated with $10 \mathrm{ng} / \mathrm{mL}$ of PDGF-BB for $15 \mathrm{~min}$. For statistical analysis, densitometry of the band representing the phosphorylated form (p-ERK1/2 and p-p38) was normalized to the expression of their respective total forms (T-ERK1/2 and T-p38). Western blot analysis of phosphorylated ERK1/2 (P-ERK1/2) and p38 MAPK (p-p38) (a) and their corresponding relative intensities $(\mathbf{b})$ and $(\mathbf{c})$. Results are presented as the mean \pm standard error of three independent experiments. Values with the same superscript letters are not significantly different as analyzed by Tukey's multiple range test $(P<0.05)$ 

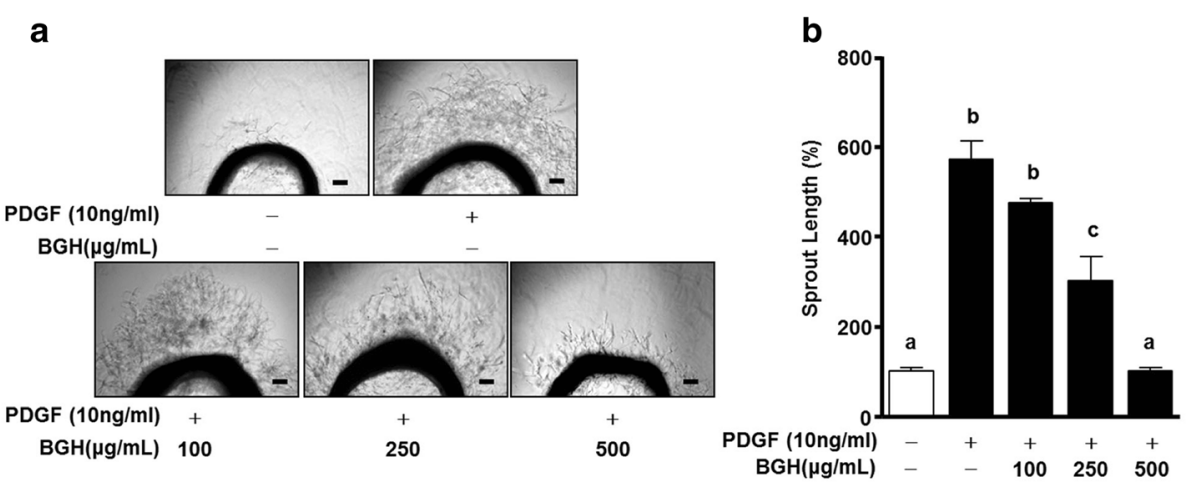

Fig. 5 Effect of Bo-Gan-Whan (BGH) on PDGF-BB-induced aortic sprout growth. The microphotographs of the aortic rings embedded in Matrigel, treated with or without BGH $(100,250$, and $500 \mu \mathrm{g} / \mathrm{mL})$ and PDGF-BB $(10 \mathrm{ng} / \mathrm{ml})$ are shown $(\mathbf{a})$. The results were observed after four days of incubation. b Also shown is the sprout outgrowth level in the untreated and BGH- and PDGF-BB-treated aortic rings, expressed as $100 \%(n=3)$. Results are presented as the mean \pm standard error of three independent experiments. Values with the same superscript letters are not significantly different as analyzed by Tukey's multiple range test $(P<0.05)$

treating pathological processes in restenosis and atherosclerosis. Moreover, the proliferative ability of various cells including VSMCs was associated closely with MAPK phosphorylation $[15,16]$. Various studies have shown that MAPKs are important signaling molecules in migration and proliferation in response to PDGF-BB stimulation in VSMCs $[7,8]$. In this study, PDGF-BB-induced proliferation and outgrowth of vessel sprouts from the aortic strips were suppressed by BGH treatment. These results imply that BGH exerts an inhibitory effect on VSMC proliferation by inhibiting pathogenic vascular remodeling.

In normal vascular function, endothelial cells prevent abnormal vascular remodeling such as hyperplasia of smooth muscle cells. However, this protective role of endothelial cells is no longer evident in patients following exposure to stents, and they become more prone to a number of risk factors that cause the narrowing of the vascular lumen $[17,18]$. Some review articles suggest

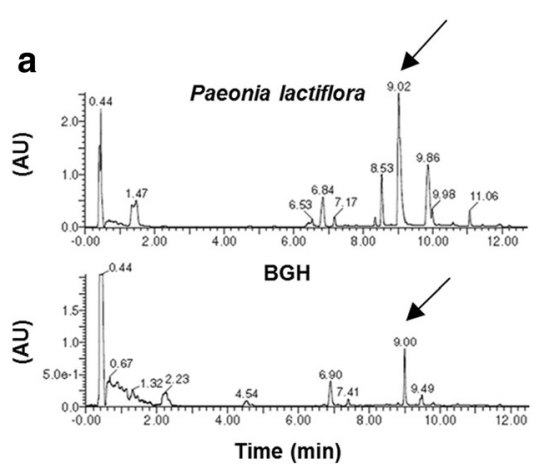

b
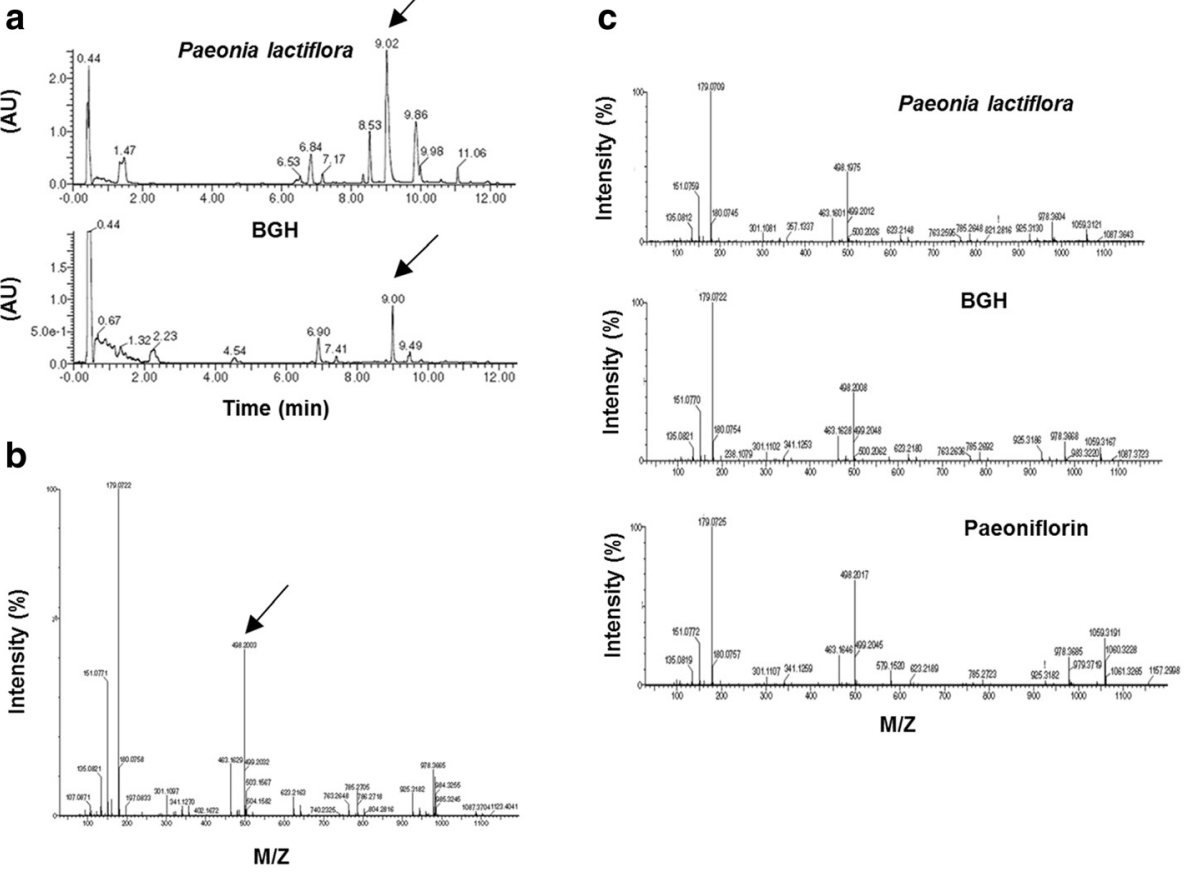

Fig. 6 UPLC-based Mass (MS) analysis of Bo-Gan-Whan (BGH). a The chromatograms of Paeonia lactiflora root (upper penal) and BGH (bottom penal) during $12 \mathrm{~min}$. The Arrows indicate the major peak of 9.01 and $9.00 \mathrm{~min}$, respectively. $\mathbf{b}$ The mass profilie in the chromatogram at 9.0 min. The arrow is indicated in 498.2003 M/Z. c MS spectra of Paeonia lactiflora root, BGH and Paeoniflorin. M/Z: mass to change ratio 
that administration of drugs and vitamins, either orally or intravenously, is essential to prevent restenosis and in-stent restenosis [19-21]. Although this therapeutic strategy has been previously tested, it has not been shown to be consistently helpful. Therefore, development of functional foods has been gaining increasing attention. For these reasons, the development of standardized and effective alternative medicine is essential $[11,12]$.

The development of atherosclerosis is strongly linked to lipid- metabolism [13, 17]. In addition to the antiatherosclerosis therapeutic activity of $\mathrm{BGH}$, it also exhibit hepato-protective effect by reducing liver damage that is strongly associated with the development of atherosclerosis. M. Ishigami et al. reported that apoE inhibits VSMC proliferation [22]. For this reason, we assume that BGH can be among those hepato-protective drug that can be prescribed in alternative in Korea. BGH can be derived from six natural sources namely Ostericum koreanum rhizome, Anglicae gigas root, Ledebouriella seseloides root, Paeonia lactiflora root, Rehmannia glutinosa root, and Cnidium officinale. Makino. Bisabolangelone, one of the active components of Ostericum koreanum, has been reported to have an anti-inflammatory effect [23]. The crude extract of Anglicae gigans Radix showed anti-tumor activity, anti-inflammation activity, and anti-aggregation of platelets. Moreover, a component of Anglicae gigans, decursin, has been reported to have anti-tumor activity [24-27]. Bergapten, is one of the major active components from Ledebouriella seseloides and has been reported to have an anti-tumor effect $[28,29]$. Paeonia Radix is the root of a traditional oriental medicinal herb named Paeonia lactiflora Pallas that has been used to treat liver diseases and has therapeutic effect in rheumatoid arthritis [30]. Rehmannia glutinosa, on the other hand, is widely used owing to its pharmacological effect on the blood system, immune system, endocrine system, cardiovascular system, and the nervous system [31]. Cnidii Rhizoma, a dried root of Cnidium officinale Makino has an anti-cancer effect [32, 33]. The extract form the rhizome of Cnidium officinale has been reported to show anti-inflammatory and anti-cancer activities [34]. Above all, the Korean polyherbal medicine, BGH has been used for liver protection. In present study, we identified paeoniflorin as the major component of BGH as revealed by the data using the UPLC. Some studies reported the paeoniflorin have hepato-protective and anti-atherosclerosis effect $[35,36]$. Therefore, we suggest that BGH may be used as a functional food for prevention atherosclerosis and restenosis.

\section{Conclusion}

The present study has demonstrated that BGH inhibits cell migration, proliferation, and phosphorylation of MAPKs in response to PDGF-BB stimulation in VSMCs.
BGH also attenuated the PDGF-BB-induced aortic sprout outgrowth. From these results, the data suggests that BGH could be a potential and a promising therapeutic agent for the development of anti-restenosis or antiatherosclerotic drugs.

\section{Acknowledgments}

This work was supported by the Dongguk University Research Fund of 2016.

\section{Funding}

The authors declare that they have received no funding for the research reported.

\section{Availability of data and materials}

The datasets supporting the conclusions of this article are presented in this main paper.

\section{Authors' contributions}

LKP contributed to the study conception and experimental design, set-up, survey design, data collection and performed analysis; and drafted and edited the manuscript. KJE participated in the study conception. $\mathrm{KH}, \mathrm{CHR}$ and LDW contributed to the revisions and performed the additional experiments that were essential to the improvement of the manuscript of this study. PWH advised design study management. All authors were involved in editing the manuscript and read and approved the final manuscript.

\section{Competing interests}

The authors declare that they have no competing interests.

\section{Consent for publication}

Not applicable.

\section{Ethics approval and consent to participate}

Present work was approved by the Ethics Committee at the Dongguk University, and all experiments were performed in accordance with the guidelines of the National Animal Care and Use Committee.

\section{Author details}

'Department of Bio-Science, College of Natural Science, Dongguk University, Dongdae-ro 123, Gyeongju, Gyeongsangbuk-do 38066, Republic of Korea.

2Department of Pathology, College of Korean Medicine, Dongguk University, Dongguk-Ro 32, Goyang, Gyeonggi-do 10326, Republic of Korea.

${ }^{3}$ Department of Diagnosis, College of Korean Medicine, Dongguk University, Dongguk-Ro 32, Goyang, Gyeonggi-do 10326, Republic of Korea.

Received: 4 February 2016 Accepted: 17 August 2016

Published online: 22 August 2016

\section{References}

1. Salomon JA, Wang H, Freeman MK, Vos T, Flaxman AD, Lopez AD, Murray CJ. Healthy life expectancy for 187 countries, 1990-2010: a systematic analysis for the Global Burden Disease Study 2010. Lancet. 2012;380(9859):2144-62.

2. Foley DP, Kererakes D, te Riele JA, Nishimura N, Veldhof S, Fink S, Yeung A, van Hoogenhuyze D, Lansky AM, van Es GA, et al. Acute and 6-month clinical and angiographic outcome after implantation of the ACS Duet stent for single-vessel coronary artery disease: final results of the European and US ACS Multi-link Duet Registry. Catheter Cardiovasc Interv. 2001;54(1):25-33.

3. Weintraub WS. The pathophysiology and burden of restenosis. Am J Cardiol. 2007;100(5A):3K-9K.

4. Bauters C, Meurice T, Hamon M, McFadden E, Lablanche JM, Bertrand ME. Mechanisms and prevention of restenosis: from experimental models to clinical practice. Cardiovasc Res. 1996;31(6):835-46.

5. Schwartz RS, Murphy JG, Edwards WD, Camrud AR, Vliestra RE, Holmes DR. Restenosis after balloon angioplasty. A practical proliferative model in porcine coronary arteries. Circulation. 1990;82(6):2190-200.

6. Marx SO, Totary-Jain H, Marks AR. Vascular smooth muscle cell proliferation in restenosis. Circ Cardiovasc Interv. 2011;4(1):104-11.

7. Ross R, Raines EW, Bowen-Pope DF. The biology of platelet-derived growth factor. Cell. 1986;46(2):155-69. 
8. Raines EW. PDGF and cardiovascular disease. Cytokine Growth Factor Rev. 2004;15(4):237-54.

9. Hellstrom M, Kalen M, Lindahl P, Abramsson A, Betsholtz C. Role of PDGF-B and PDGFR-beta in recruitment of vascular smooth muscle cells and pericytes during embryonic blood vessel formation in the mouse. Development. 1999;126(14):3047-55.

10. Lee CK, Lee HM, Kim HJ, Park HJ, Won KJ, Roh HY, Choi WS, Jeon BH, Park TK, Kim B. Syk contributes to PDGF-BB-mediated migration of rat aortic smooth muscle cells via MAPK pathways. Cardiovasc Res. 2007;74(1):159-68.

11. Hasler CM, Kundrat S, Wool D. Functional foods and cardiovascular disease. Curr atheroscler Rep. 2000;2(6):467-75.

12. Kris-Etherton PM, Etherton TD, Carlson J, Gardner C. Recent discoveries in inclusive food-based approaches and dietary patterns for reduction in risk for cardiovascular disease. Curr Opin Lipidol. 2002;13(4):397-407.

13. Erl W. Statin-induced vascular smooth muscle cell apoptosis: a possible role in the prevention of restenosis? Curr Drug Targets Cardiovasc Haematol Disord. 2005;5(2):135-44.

14. Jun JH, Choi TY, Lee JA, Yun KJ, Lee MS. Herbal medicine (Gan Mai Da Zao decoction) for depression: a systematic review and meta-analysis of randomized controlled trials. Maturitas. 2014;79(4):370-80.

15. Lee KP, Park ES, Kim DE, Park IS, Kim JT, Hong H. Artemisinin attenuates platelet-derived growth factor BB-induced migration of vascular smooth muscle cells. Nutr Res Pract. 2014;8(5):521-5.

16. Lee KP, Lee K, Park WH, Kim H, Hong H. Piperine inhibits platelet-derived growth factor-BB-induced proliferation and migration in vascular smooth muscle cells. J Med Food. 2015;18(2):208-15.

17. Minamino T, Miyauchi H, Yoshida T, Komuro I. [Endothelial cell senescence in human atherosclerosis: role of telomeres in endothelial dysfunction]. J Cardiol. 2003;41(1):39-40.

18. Gerthoffer WT. Mechanisms of vascular smooth muscle cell migration. Circ Res. 2007;100(5):607-21.

19. Gidlof AC, Ocaya P, Krivospitskaya O, Sirsjo A. Vitamin A: a drug for prevention of restenosis/reocclusion after percutaneous coronary intervention? Clin Sci. 2008;114(1):19-25.

20. Zargham R. Preventing restenosis after angioplasty: a multistage approach Clin Sci. 2008;114(4):257-64.

21. Lafont AM, Chai YC, Cornhill JF, Whitlow PL, Howe PH, Chisolm GM. Effect of alpha-tocopherol on restenosis after angioplasty in a model of experimental atherosclerosis. J Clin Invest. 1995;95(3):1018-25.

22. Ishigami M, Swertfeger DK, Hui MS, Granholm NA, Hui DY. Apolipoprotein E inhibition of vascular smooth muscle cell proliferation but not the inhibition of migration is mediated through activation of inducible nitric oxide synthase. Arterioscler Thromb Vasc Biol. 2000;20(4):1020-6.

23. Jung HW, Mahesh R, Park JH, Boo YC, Park KM, Park YK. Bisabolangelone isolated from Ostericum koreanum inhibits the production of inflammatory mediators by down-regulation of NF-kappaB and ERK MAP kinase activity in LPS-stimulated RAW264.7 cells. Int Immunopharmacol. 2010;10(2):155-62.

24. Lee S, Lee YS, Jung SH, Shin KH, Kim BK, Kang SS. Anti-tumor activities of decursinol angelate and decursin from Angelica gigas. Arch Pharm Res. 2003;26(9):727-30.

25. Shin S, Joo SS, Park D, Jeon JH, Kim TK, Kim JS, Park SK, Hwang BY, Kim YB, Ethanol extract of Angelica gigas inhibits croton oil-induced inflammation by suppressing the cyclooxygenase - prostaglandin pathway. J Vet Sci. 2010;11(1):43-50.

26. Lee YY, Lee S, Jin JL, Yun-Choi HS. Platelet anti-aggregatory effects of coumarins from the roots of Angelica genuflexa and A. gigas. Arch Pharm Res. 2003;26(9):723-6.

27. Ahn KS, Sim WS, Lee IK, Seu YB, Kim IH. Decursinol angelate: a cytotoxic and protein kinase $\mathrm{C}$ activating agent from the root of Angelica gigas. Planta Med. 1997;63(4):360-1.

28. Jin G, Li J, Piao H. [Chemical constituents of Ledebouriella seseloides Wolff]. Zhongguo Zhong Yao Za Zhi. 1992;17(1):38-40. 64.

29. Panno ML, Giordano F, Palma MG, Bartella V, Rago V, Maggiolini M, Sisci D, Lanzino M, De Amicis F, Ando S. Evidence that bergapten, independently of its photoactivation, enhances p53 gene expression and induces apoptosis in human breast cancer cells. Curr Cancer Drug Targets. 2009;9(4):469-81.

30. Zhang W, Dai SM. Mechanisms involved in the therapeutic effects of Paeonia lactiflora Pallas in rheumatoid arthritis. Int Immunopharmacol. 2012;14(1):27-31.

31. Zhang RX, Li MX, Jia ZP. Rehmannia glutinosa: review of botany, chemistry and pharmacology. J Ethnopharmacol. 2008;117(2):199-214.
32. Haranaka K, Satomi N, Sakurai A, Haranaka R, Okada N, Kobayashi M. Antitumor activities and tumor necrosis factor producibility of traditional Chinese medicines and crude drugs. Cancer Immunol Immunother. 1985:20(1):1-5.

33. Onishi Y, Yamaura T, Tauchi K, Sakamoto T, Tsukada K, Nunome S, Komatsu Y, Saiki I. Expression of the anti-metastatic effect induced by Juzen-taiho-to is based on the content of Shimotsu-to constituents. Biol Pharm Bull. 1998;21(7):761-5.

34. Bae KE, Choi YW, Kim ST, Kim YK. Components of rhizome extract of Cnidium officinale Makino and their in vitro biological effects. Molecules. 2011;16(10):8833-47.

35. Zhang L, Yang B, Yu B. Paeoniflorin Protects against Nonalcoholic Fatty Liver Disease Induced by a High-Fat Diet in Mice. Biol Pharm Bull. 2015;38(7):1005-11.

36. Chen YF, Wu KJ, Wood WG. Paeonia lactiflora Extract Attenuating Cerebral Ischemia and Arterial Intimal Hyperplasia Is Mediated by Paeoniflorin via Modulation of VSMC Migration and Ras/MEK/ERK Signaling Pathway. Evid Based Complement Alternat Med. 2013;2013:482428.

\section{Submit your next manuscript to BioMed Central and we will help you at every step:}

- We accept pre-submission inquiries

- Our selector tool helps you to find the most relevant journal

- We provide round the clock customer support

- Convenient online submission

- Thorough peer review

- Inclusion in PubMed and all major indexing services

- Maximum visibility for your research

Submit your manuscript at www.biomedcentral.com/submit
Biomed Central 